\title{
Effects of Historical Urbanization in the Brussels Capital Region on Surface Air Temperature Time Series: A Model Study
}

\author{
R. Hamdi, A. Deckmyn, P. Termonia, G. R. Demarée, and P. Baguis \\ Royal Meteorological Institute, Brussels, Belgium \\ S. VANHUYSSE AND E. WOLFF \\ IGEAT, Faculty of Sciences, Free University of Brussels, Brussels, Belgium
}

(Manuscript received 8 October 2008, in final form 21 April 2009)

\begin{abstract}
The authors examine the local impact of change in impervious surfaces in the Brussels capital region (BCR), Belgium, on trends in maximum, minimum, and mean temperatures between 1960 and 1999. Specifically, data are combined from remote sensing imagery and a land surface model including state-of-the-art urban parameterization - the Town Energy Balance scheme. To (i) isolate effects of urban growth on nearsurface temperature independent of atmospheric circulations and (ii) be able to run the model over a very long period without any computational cost restrictions, the land surface model is run in a stand-alone mode coupled to downscaled 40-yr ECMWF reanalysis data. BCR was considered a lumped urban volume and the rate of urbanization was assessed by estimating the percentage of impervious surfaces from Landsat images acquired for various years. Model simulations show that (i) the annual mean urban bias (AMUB) on minimum temperature is rising at a higher rate (almost 3 times more) than on maximum temperature, with a linear trend of $0.14^{\circ}$ and $0.05^{\circ} \mathrm{C}(10 \mathrm{yr})^{-1}$, respectively, (ii) the 40 -yr AMUB on mean temperature is estimated to be $0.62^{\circ} \mathrm{C}$, (iii) $45 \%$ of the overall warming trend is attributed to intensifying urban heat island effects rather than to changes in local-regional climate, and (iv) during summertime, a stronger dependence between the increase of urban bias on minimum temperature and the change in percentage of impervious surfaces is found.
\end{abstract}

\section{Introduction}

The Brussels capital region (BCR) in Belgium has experienced a rapid overturning of agricultural land and native vegetation to buildings and impermeable pavements over the last century. In fact, while the population of the present BCR was only 140000 in 1831, the number of inhabitants had risen to about 1 million in 2004, which caused a massive expansion of the capital. In terms of ecological impact, urbanization is one of the most significant and long lasting forms of land use and cover change and its extent of increase is linked to population growth and economic development. At the same time, a gradual increase in temperatures has been observed at the national recording station of the Royal Meteorological Institute (RMI) of Belgium (1833-present), which is located some $6 \mathrm{~km}$ south of the center of the

Corresponding author address: R. Hamdi, Royal Meteorological Institute, Avenue Circulaire, 3, B-1180 Brussels, Belgium.

E-mail: rafiq.hamdi@oma.be capital, in the Uccle suburb. This time series has been used to monitor climate change in Belgium and is used in the world database of land surface air temperatures and in the Global Climate Observing System (GCOS) surface network (Peterson et al. 1997). The temperature time series of Uccle has always been used as a rural station, whereas it is actually one of those series suspected of being influenced by the urban heat island (UHI) created by the surrounding growing urban areas.

The past observational approach (Vandiepenbeeck 1998) has focused on empirical evidence for the UHI contamination in this temperature record. Vandiepenbeeck (1998) compared air temperature records at Uccle with records of a rural area as a function of meteorological conditions. However, in situ observations usually suffer from inhomogeneities caused by nonclimatic factors such as changes in observation time, instrumentation, location (altitude and latitude), and other local meteorological features. Aguilar et al. (2003) and Wijngaard et al. (2003) have determined guidelines for climatological metadata and homogenization procedures. These 
factors could introduce artifacts in long-term observations and rural/urban differences and thus may bias the estimate of the UHI. Recently, Van Weverberg et al. (2008) used a modeling approach to study the influence of the UHI development on temperature recordings at Uccle. The method consists of evaluating the simulated temperature difference of two model integrations initialized with different land cover patterns: (i) the model was integrated using the contemporaneous land cover setting as input, (ii) the model was integrated with a land cover setting similar to the one at the time the recording station was set up about $170 \mathrm{yr}$ ago, but with otherwise identical initial and boundary conditions as in the first run. The model was applied using one-way grid nesting with three levels, the later being a domain of $60 \mathrm{~km} \times$ $60 \mathrm{~km}$ centered on Brussels with a horizontal resolution of $1 \mathrm{~km}$. Van Weverberg et al.'s (2008) investigations (see their Fig. 5) revealed that the temperature gradient from the rural environment toward the urban site is quite strong, while in the built area a temperature plateau is obvious with the Uccle station being within this area influenced by urban heating. However, the model runs were restricted to a few weather episodes given the large computational costs of simulations. Thus no representative urban bias corrections for the time series at Uccle can be derived from their simulations.

With the advent of remote sensing methodology, it has become possible to monitor local urban climate changes associated with land use changes over rapidly expanding urban areas like BCR. Specifically, the quantity of impervious surfaces is related to urban growth and urban density (Fricke and Wolff 2002; Vanhuysse et al. 2006). The proportion of impervious surfaces has been reported to be a good indicator for the monitoring of the UHI. A positive correlation between the proportion of impervious surfaces and land surface temperatures was identified by Yuan and Bauer (2007). The expansion of the built-up area was found to be the main factor in longterm changes in air temperatures (Huang et al. 2008; Shouraseni and Yuan 2009). Therefore, in this study we will update previous research by analyzing the local impact of change in impervious surfaces in the BCR on long-term trends in maximum, minimum, and mean temperatures between 1960 and 1999. Specifically, we combine data from remote sensing imagery and a land surface model including the urban parameterization of Masson (2000), called the Town Energy Balance (TEB) scheme. In the present study, (i) we use the land surface model in a stand-alone mode, coupled to downscaled 40-yr European Centre for Medium-Range Weather Forecasts (ECMWF) reanalysis (ERA-40) data, to isolate the local effects of urban growth on near-surface temperature independent of atmospheric circulations
(Bounoua et al. 2009), (ii) we consider BCR as a lumped urban volume (Silva et al. 2009) with the underlying assumption that the entire BCR is composed of one homogeneous material comprising uniform thermophysical properties, irrespective of spatial variability. These hypotheses will enable us to simplify an extremely complex problem - the urban environment-but keeps intact the surface energy balance. Urbanization was assessed by measuring changes of the impervious surface areas (percent) in the BCR. It should be noted that it is the first time a modeling approach is applied to assess the degree to which background temperature trends are amplified by urbanization.

\section{Data and model}

\section{a. Study area}

The focus of our study is the Brussels capital region, centrally located in Belgium (see Fig. 1), with a size of $161.78 \mathrm{~km}^{2}$ and a registered population of 1031215 on 1 January 2007, estimated by the National Institute of Statistics (INS). As in the majority of large European cities, it is only during the nineteenth century that the population strongly increased, exceeding 1 million inhabitants in 2004. This caused a massive expansion of the capital during the last $150 \mathrm{yr}$. Relative to some other European capitals, Brussels is, however, a green city. In fact, according to an inventory made in 1999 by the Brussels Institute of Environmental Management (BIM), the city has 8563 ha of green areas, which is $53 \%$ of the total area (Van de Voorde et al. 2008). The area covered by the BCR is quite circular (Fig. 1) with a diameter of $12 \mathrm{~km}$, and the effects of urbanization variability dominate the topographic influence (orography is beneath $100 \mathrm{~m}$ ).

The national recording station of RMI of Belgium [World Meteorological Organization (WMO) code 06447] is situated some $6 \mathrm{~km}$ south of the center of the capital (Fig. 1), in the Uccle suburb, at $50.80^{\circ} \mathrm{N}$ and $04.35^{\circ} \mathrm{E}$, at $104 \mathrm{~m}$ above sea level. This time series has a long history, dating to 1833 , and has been constructed within the EU IMPROVE project that focused upon the construction of time series of early daily European instrumental observations (Camuffo and Jones 2002). In this context, the homogenization of climatological time series was a major issue. In particular, corrections due to changes in the thermometers and instrument corrections have been applied to the Royal Observatory of Brussels part of the series (since 1833). The daily mean temperature has been determined from the 1870 s onward by the arithmetic mean of the daily minimum and maximum temperature. Furthermore, the single relocation from 


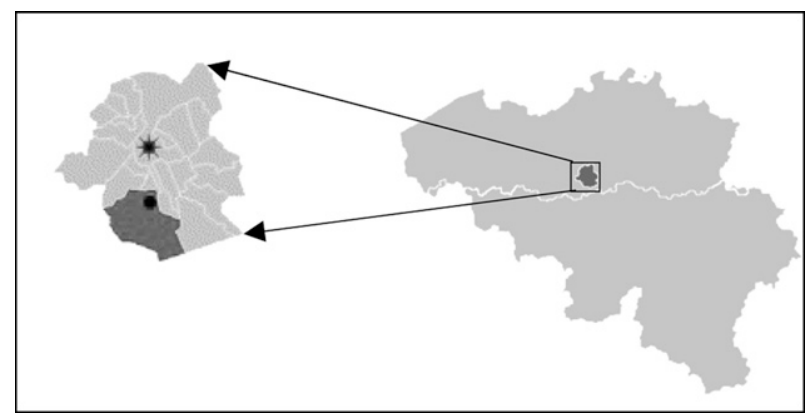

FIG. 1. (right) Belgium and (left) BCR. The black asterisk marks the city center of Brussels, and the black circle marks the location of the national recording station of the RMI, situated some $6 \mathrm{~km}$ south of the center, in the Uccle suburb (shaded).

the Gate of Schaerbeek in the city center of Brussels to the Plateau of Uccle in 1890 was duly taken into account. More details about the homogenization of the time series of Uccle can be found in Demarée et al. (2002) and Sneyers (1981)

However, the impact of urbanization of the station environment has not been assessed in this time series. The signal of urban warming of the city of Brussels is embedded together with other aspects such as global warming within the temperature time series of Uccle. The Uccle mean annual time series together with the mean annual worldwide time series as given by the Climatic Research Unit (CRU)/Hadley Center and by the National Aeronautics and Space Administration Goddard Institute for Space Studies (NASA GISS) are shown in Fig. 2. All values are calculated as deviations from the 1951-80 period. An abrupt change in the Uccle time series is noted by the end of the 1980s. Recent research by Van Oldenborgh and Van Ulden (2003) and Van Oldenborgh et al. (2009) showed that the observed temperature trend in western Europe over the last decades appears much stronger than that simulated by state-of-the-art general circulation models (GCMs). The aim of the present study is to quantify which part of this warm bias with respect to the global trend can be explained by urbanization of the city of Brussels.

\section{b. Model}

We use the newly developed surface scheme of Météo-France-Surface Externalisée (SURFEX; Le Moigne 2009). SURFEX is an externalized surface scheme that can be run either in a coupled mode in which case the atmospheric forcing is provided by the host atmospheric model, or in a stand-alone mode where the atmospheric drivers are derived from observations and fed to the surface scheme such that it is decoupled from the atmospheric part of a global circulation model. The latter case is possible by relying on the algorithmic structure proposed by Best et al. (2004). SURFEX contains various modules allowing one to describe the exchanges of water, momentum, and energy over four tof surface area tiles: sea, lake, vegetation, and the city. A grid value is then simply an area averaged value of the different tiles present in the grid cell.

Over vegetated areas, SURFEX includes the Noilhan and Planton (1989) Interactions between Soil, Biosphere, and Atmosphere (ISBA) scheme. ISBA solves simultaneously the energy and water budget of the soil and vegetation. Vegetation parameters come from the "Ecoclimap" database (Masson et al. 2003). Over urban surfaces, SURFEX includes the Town Energy Balance (Masson 2000) single-layer urban canopy module. Urban canopy is assumed to be an isotropic array of street canyons. TEB simulates heat and water exchanges of three generic surfaces (roof, wall, and road), where heat transfers are computed through several layers of materials, generally four. Anthropogenic heat and vapor releases from buildings, vehicles, and chimneys can also be added. TEB is forced with literature-based surface thermal parameters and observed or simulated atmospheric and radiation data from above roof level. Despite the simplification hypotheses, offline simulations of TEB have been shown to accurately reproduce surface energy

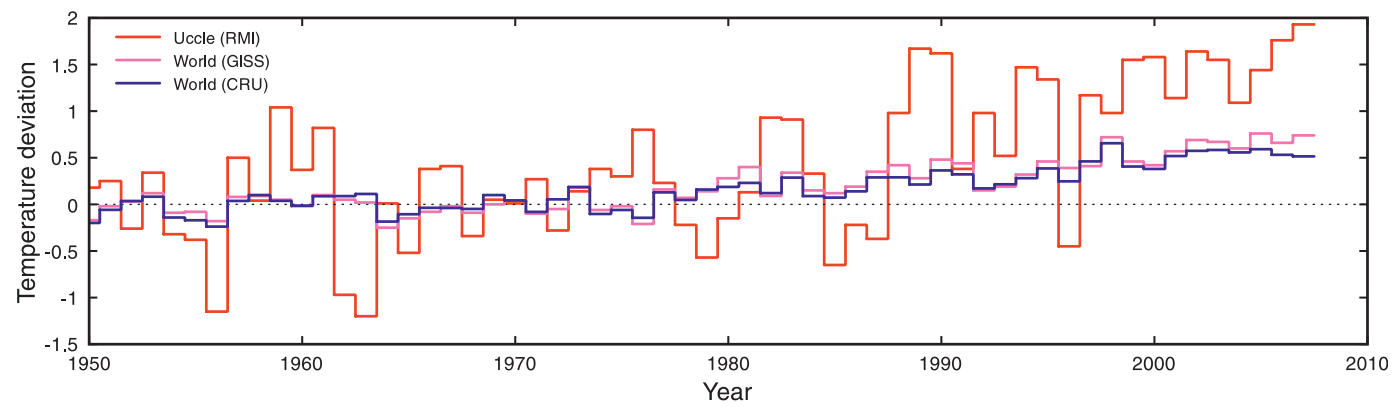

FIG. 2. Mean annual time series of the Uccle temperature (red) and the worldwide CRU/Hadley (blue) and NASA GISS (pink) temperature. All values are shown as deviations from their 1951-80 means. 
balance, canyon air temperature, and surface temperatures observed in dense urban areas-Vancouver and Mexico City (Masson et al. 2002), Marseille (Lemonsu et al. 2004), Basel (Hamdi and Masson 2008)—during dry and hot seasons. In the study by Pigeon et al. (2008), the evaluation of TEB is extended to two other seasons, fall and winter. In their study, a validation of the parameterization of anthropogenic heat sources against an inventory of energy consumption in the city of Toulouse, France, was also performed.

In the present study SURFEX is coupled to a surface boundary layer (SBL) scheme following the methodology described in Masson and Seity (2009). With this version, several prognostic air layers are added from the ground up to the forcing level and the surface boundary layer is, thus, resolved prognostically, taking into account large-scale forcing, turbulence, and if any, drag and canopy forces. The interest of this approach is to use the advanced physical description of the SBL-canopy interactions that was available only in complex coupled multilayer surface schemes in offline surface schemes [see Masson and Seity (2009) for more details].

In the present study, we use SURFEX_SBL in a standalone mode to (i) isolate the effects of urbanization on local near-surface temperature independent of atmospheric circulations, and (ii) run the model over a very long period without any computational cost restrictions.

\section{c. Data}

\section{1) ATMOSPHERIC DATA}

ERA-40 (Uppala et al. 2005), produced by the European Centre for Medium-Range Weather Forecasts, is a global dataset covering the period from September 1957 to August 2002 at a temporal resolution of 6 h. For western Europe, it has a spatial resolution of about $120 \mathrm{~km}$. To increase the spatial resolution above Belgium, dynamical downscaling was applied using the limited area model (LAM) Aire Limitée Adaptation Dynamique Développement International (ALADIN) developed by the ALADIN International Team (1997) (ALADIN is running operationally at the Royal Meteorological Institute of Belgium). The method is essentially equivalent to that described by Žagar et al. (2006).

We opted for a nested downscaling to $10-\mathrm{km}$ resolution in two steps. In the first step, the ALADIN model is coupled to the ERA- 40 data and run at a resolution of $40 \mathrm{~km}$ on a domain encompassing most of western Europe. The results from this run are then used as initial conditions and lateral boundary conditions for a second downscaling run at $10-\mathrm{km}$ resolution on a smaller domain over Belgium. In, for example, Qian et al. (2003), it was shown that one should not let a regional model run un- attended for a long period of time. After a number of days, the model diverges from the coupling data to arrive at some (constant) bias. To avoid this, it is necessary to reinitialize the downscaling run. We chose to do this daily. Our downscaling strategy may thus be summarized in the following steps:

1) The original ERA-40 files are interpolated to $40-\mathrm{km}$ resolution.

2) These 6-hourly files serve as initial and boundary conditions for a 48-h ALADIN run at 40-km resolution. These are started at 0000 UTC every day.

3) The (3-hourly) output from this first run serves as input for a $10-\mathrm{km}$ run of ALADIN. However, to avoid spinup problems, the first $12 \mathrm{~h}$ are not taken into account. So we have $36-\mathrm{h}$ data left for the $10-\mathrm{km}$ runs (which thus start at 1200 UTC).

4) Finally, we again dismiss the first $12 \mathrm{~h}$ of the run, to arrive at $24 \mathrm{~h}$ of (3-hourly) ALADIN output at 10-km resolution.

\section{2) EVOLUTION OF SURFACE COVER FRACTIONS}

The evolution of surface cover fractions over BCR was derived from the Vanhuysse et al. (2006) study. This study aims to assess the evolution of the fraction of impervious surfaces in the catchment basins including BCR since the 1950s date of the acceleration of urban growth linked to widespread use of cars as a new mode of transport. Two periods were studied.

1) For the 1950s-1980s, Vanhuysse et al. (2006) used the "MURBANDY" database (Fricke and Wolff 2002) available for 1955, 1970, and 1985 and then estimated the fraction of impervious surfaces using topographic maps and aerial photos. The results indicate that the percentage of impervious surfaces has increased from $26 \%$ in 1955 to $39 \%$ in 1985 .

2) For the 1980s-2006, Vanhuysse et al. (2006) first conducted a classification of land use on the basis of a satellite image at very high resolution (UrbOrtho $0.6 \mathrm{~m}$, QuickBird $2.4 \mathrm{~m}$ ) dating from 2006. Then, starting from a binary classification (vegetated and impervious surfaces), they built a simple regression model between the percentage of impervious surfaces and different spectral variables derived from high-resolution satellite images. This model permitted an estimate of the percentage of impervious surfaces for two previous dates (1993 and 1986) for which only high-resolution images (Landsat Thematic Mapper with $30-\mathrm{m}$ resolution) are available. The results indicate that the percentage of impervious surfaces has increased from 39\% in 1985 to $47 \%$ in 2006. 
Figure 3 shows that the increase in impervious surfaces is very important since the 1950 s, from $26 \%$ in $1955 \%$ to $47 \%$ in 2006 , almost doubling. The largest increase (both in absolute and relative terms) occurs between 1955 and 1970. Then a slight decline in the upward trend is observed. Between 1985 and 1993, there was a decline in growth due to a crisis in the real estate market during the 1980s. After 1993, the increase in impervious surface becomes again very important, remaining so until now. The results presented here reflect the reality but it must be kept in mind that different data information and methods were used, and therefore we should tolerate a margin of error of a few percent over the areas studied (Vanhuysse et al. 2006; Van de Voorde et al. 2008).

Figure 4 shows the spatial distribution of the percentage of impervious surfaces in the catchment basins including BCR in 1955, 1970, 1985, and 2006. Figure 4 clearly reveals that as Brussels grows the Uccle observatory becomes surrounded by impervious surfaces with increasing percentage over time. In fact, the change in urbanization over time is smaller for a station that originally was established in a densely built-up area than for a station originally installed in a rural or only light urbanized environment that has experienced growth.

\section{Model input parameter}

We selected a small heterogeneous domain, $(10 \mathrm{~km} \times$ $10 \mathrm{~km}$ ) over the BCR, centered at the city center of Brussels and covering the temperature plateau area mentioned in the introduction. We overlaid that domain over a 1-km-resolution land cover classification provided by the Ecoclimap database. The land cover types contained in this domain are then aggregated into four tiles (sea, lake, vegetation, and urban) with the corresponding fractional coverage $(0 \%, 0 \%, 53 \%$, and $47 \%)$ to be used as the contemporaneous land cover setting. We run the model in an offline single-column mode from 1 January 1950 to 31 December 1999 (40 yr). The forcing data consist of 3-hourly air temperature, specific humidity, atmospheric pressure, incoming global radiation, incoming longwave radiation, precipitation rate, and wind speed. These data are then temporally interpolated to get data with the time resolution of the integration scheme of SURFEX_SBL (300 s). These drivers are taken at a height of $50 \mathrm{~m}$ above ground level (AGL) to ensure that they are representative of the local scale $\left(10^{2}-10^{4} \mathrm{~m}\right)$. SURFEX_SBL calculates the meteorological variables from this forcing level down to the ground (SBL levels are chosen at 1,3,10,20,30, and $50 \mathrm{~m}$ AGL).

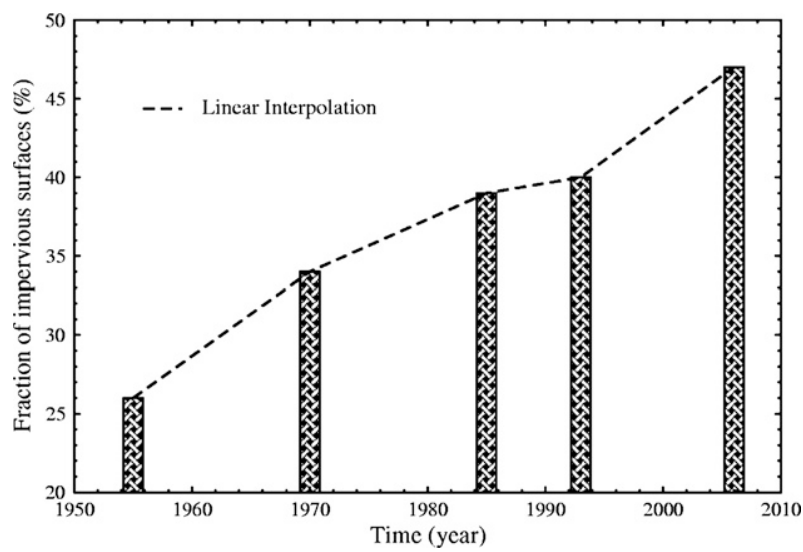

FIG. 3. Evolution of the average percent imperviousness of the BCR from 1955 to 2006.

In SURFEX_SBL, the prognostic variables (e.g., surface and canopy temperature) are rather fast response variables and their initialization does not present a problem since they adjust over few time steps. In this study they are initialized using the initial values from the drivers. To isolate effects of urbanization on local near-surface climate conditions, we performed model simulations according to two scenarios, which correspond to different states of urbanization.

1) The "rural" scenario represented a hypothetical situation with no urban areas inside the domain during the $40 \mathrm{yr}$. Radiative and thermal properties of the vegetation cover (albedo, roughness length, emissivity, thermal inertia, leaf area index, etc.) are taken from the Ecoclimap database (Masson et al. 2003) and remain fixed throughout the simulation. Changes of these properties due to vegetation dynamics were not included in the present study.

2) The "urban" scenario represented the climate in the presence of urban areas using the evolution of surface cover fractions (see Fig. 3). For this run, the surface cover fractions are updated each year using a linear interpolation. For the urban tile, SURFEX_SBL uses only one urban land use class as input, which is characterized by a set of parameters. In this study, geometrical, thermal, and radiative properties of roofs, walls, and roads were averaged over available data (Masson et al. 2002; Lemonsu et al. 2004; Hamdi and Schayes 2007, 2008; Hamdi and Masson 2008; Trusilova et al. 2008; Pigeon et al. 2008) and were set to values representing a typical midsize European city (see Table 1). These properties remained fixed through the simulations. Another important urbanrelated aspect is the anthropogenic heat. This term includes all heat emitted by human activities: traffic, release from industry, and release from residential 


\section{Percentage of impervious surfaces}

in 1-ha grid cells : 1955

( Uccle observatory

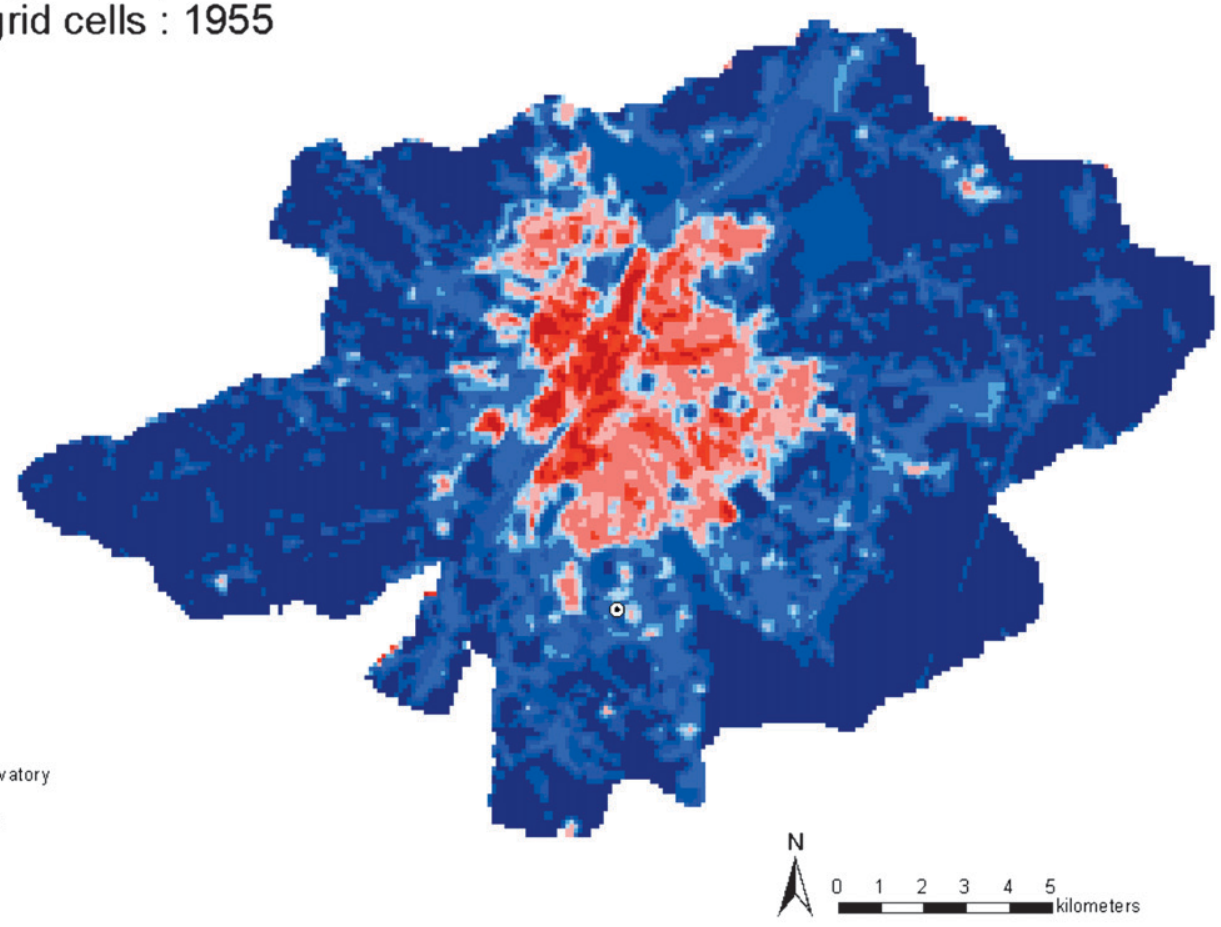

\section{Percentage of impervious surfaces}

in 1-ha grid cells : 1970
- Uccle observatory
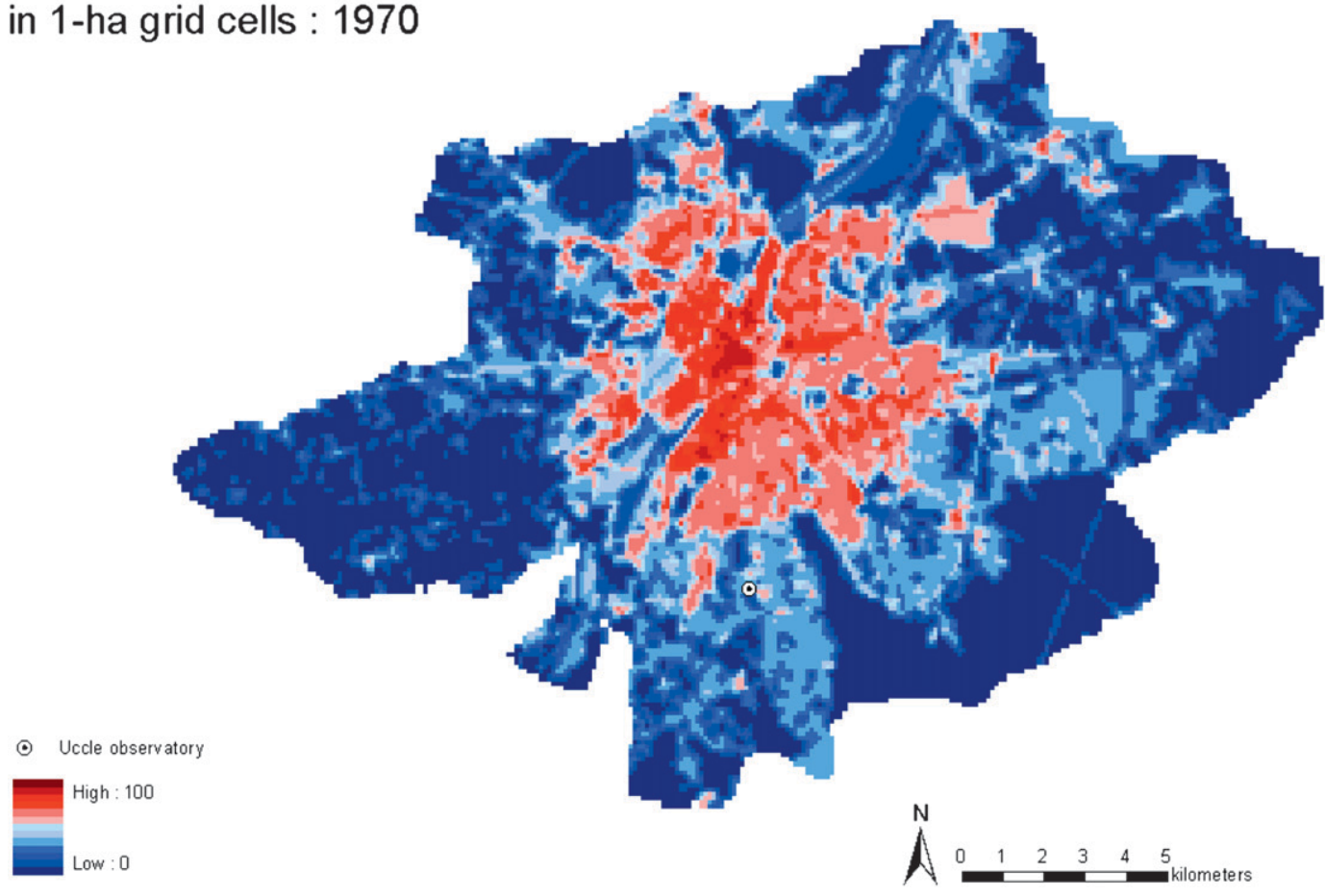

FIG. 4. The percentage of impervious surfaces in the catchment basins including the BCR in 1955, 1970, 1985, and 2006. The black dot shows the Uccle observatory location. 
Percentage of impervious surfaces

in 1-ha grid cells : 1985

(-) Uccle observatory

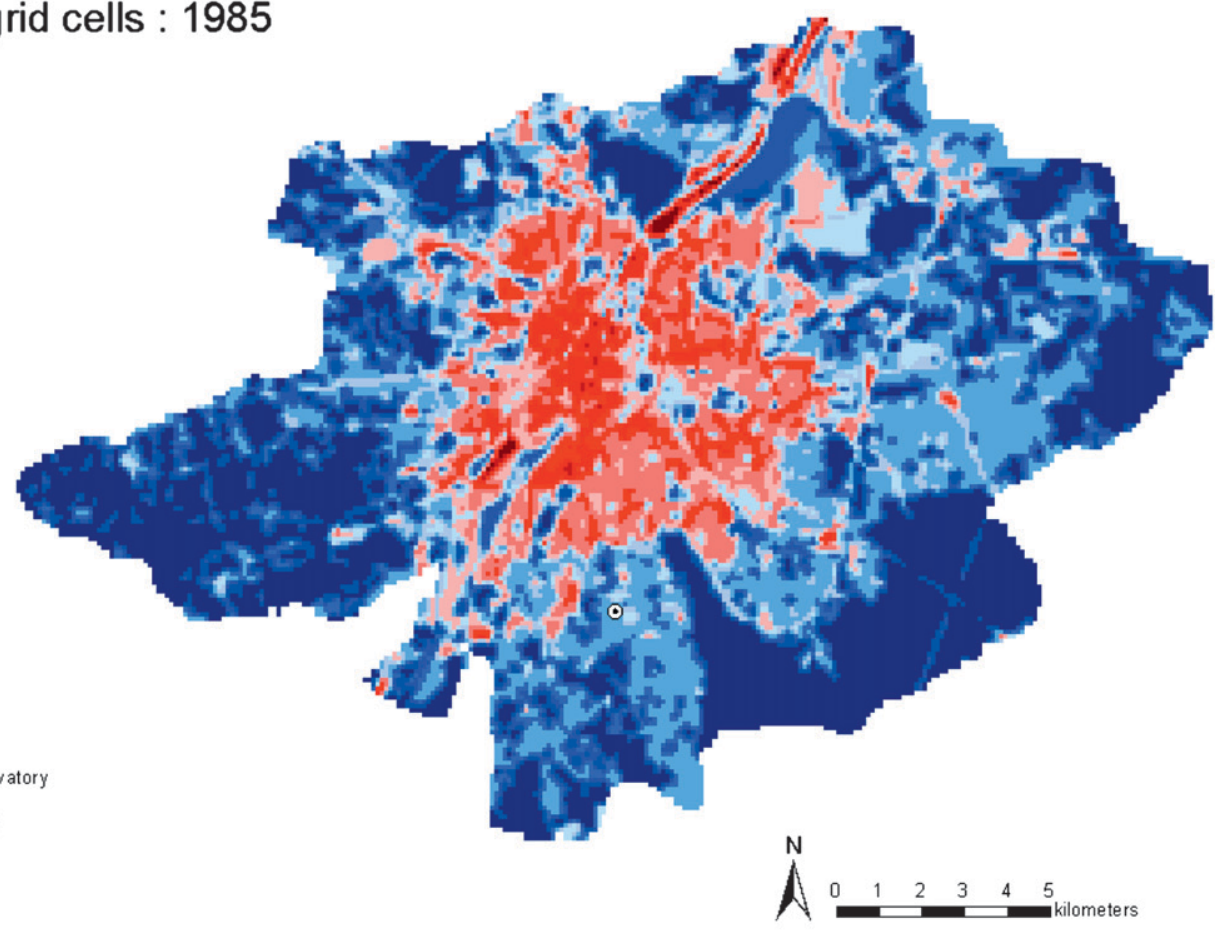

Percentage of impervious surfaces

in 1-ha grid cells : 2006

(-) Uccle observatory

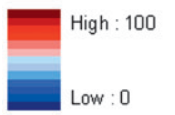

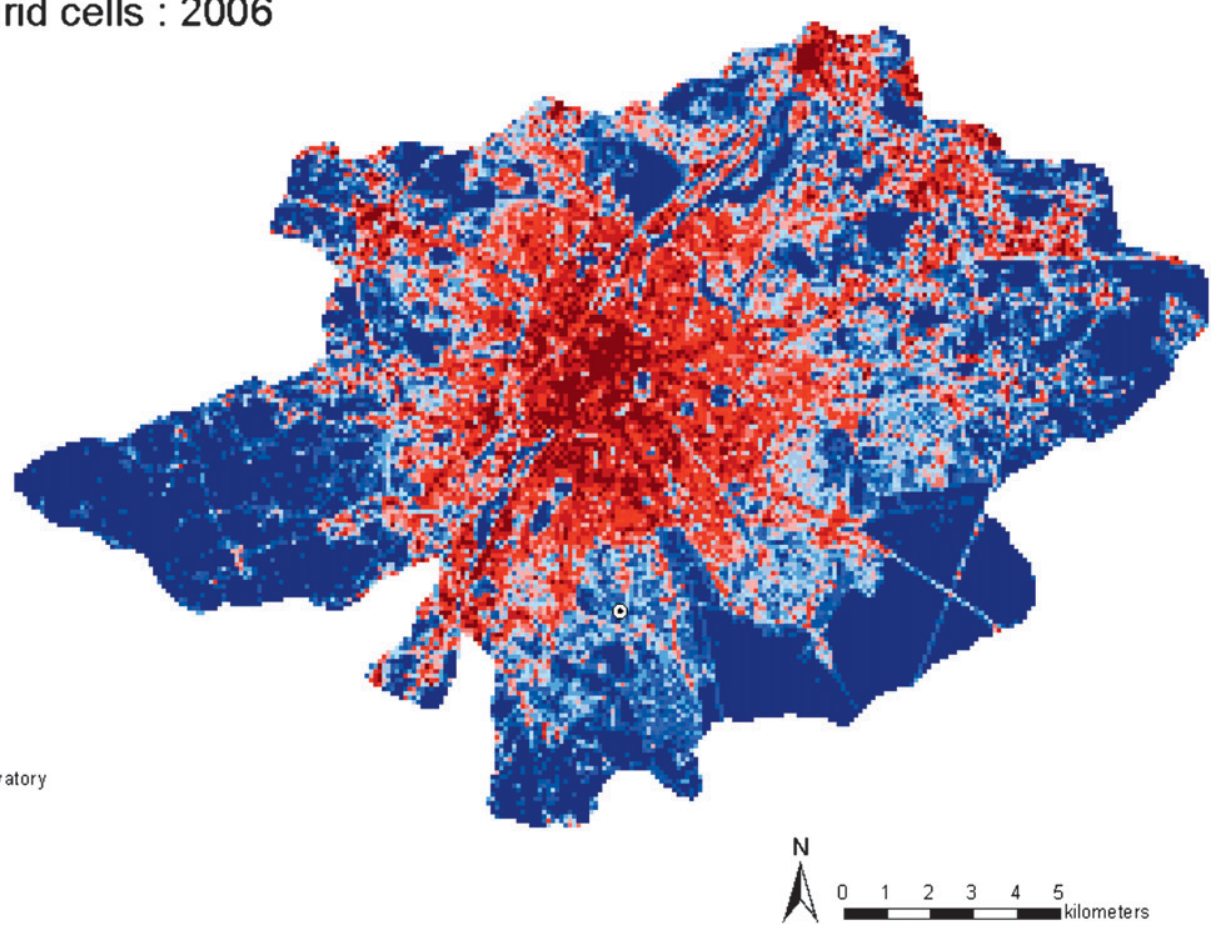

FIG. 4. (Continued) 
TABLE 1. 3D morphometric parameters of BCR (characterized as a typical midsize European city) and the physical properties of urban elements used in the model.

\begin{tabular}{lc}
\hline \hline Cover fraction & \\
Vegetation & 0.53 \\
Water & 0.00 \\
Urban & 0.47 \\
Morphometric parameters & $20 \mathrm{~m}$ \\
Mean building height & 1 \\
Local canyon height/width ratio & 0.50 \\
Plan aspect ratio of buildings & 0.50 \\
Frontal aspect ratio of buildings & \\
Road properties & Asphalt and concrete \\
Mean materials & over dry soil \\
& 0.08 \\
Albedo & 0.94 \\
Emissivity & $0.05 \mathrm{~m}$ \\
Momentum roughness length & \\
Roof properties & Plaster, concrete, brick \\
Mean materials & 0.14 \\
& 0.90 \\
Albedo & \\
Emissivity & 0.14 \\
Momentum roughness length & 0.90 \\
Wall properties & $0.15 \mathrm{~m}$ \\
Mean materials & \\
Albedo & \\
Emissivity & corrugated iron \\
\hline
\end{tabular}

buildings. Over the area presented in this study, releases from buildings have been shown to be the dominant component of the anthropogenic heat (Van Weverberg et al. 2008). In SURFEX_SBL, to mimic space heating, a fixed minimum internal building temperature of $19^{\circ} \mathrm{C}$ is specified (Masson 2000; Masson et al. 2002; Pigeon et al. 2008). During fall or winter, internal wall and roof surface temperatures often have values below this threshold, and the heat flux between the internal volume of the building and the wall (or the roof) is directed out of the buildings. An evaluation of this parameterization of anthropogenic heat sources against an inventory of energy consumption for the city of Toulouse was performed in Pigeon et al. (2008).

Each simulation starts from the same initial conditions and runs forward for $40 \mathrm{yr}$ using the same climate drivers so that the model responses are exclusively attributable to land cover change. The use of the land surface model in an offline mode does not account for atmospheric feedback and therefore allows isolation of the effects of landscape difference on local near-surface climate conditions. The difference in simulated temperature of both model integrations is an estimate of the local urbanization impact in the local observed temperature record. It should be noted that since in this

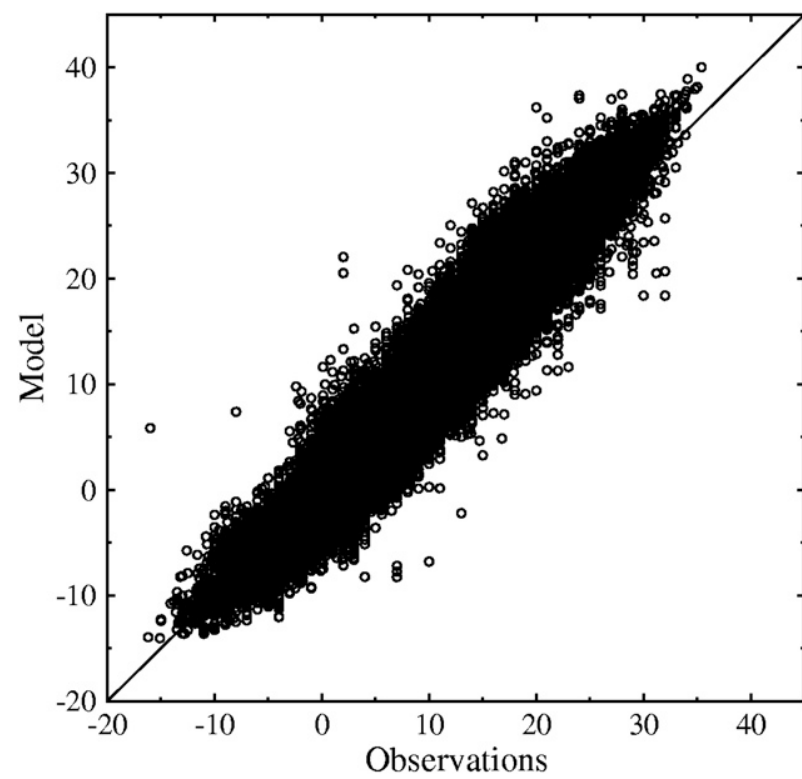

FIG. 5. Scatterplots of model predictions vs observations of 2-m temperature $\left({ }^{\circ} \mathrm{C}\right)$ at the Uccle ground stations.

study the effect of urban growth is treated in isolation to climatic change of the general circulation, the local temperature change can either be exacerbated or diminished by the effects of large-scale circulation.

\section{Results and discussion}

\section{a. Evaluation of the model}

To evaluate model performance, a comparison is made between the urban run and the routine observations of the Uccle ground station. A scatterplot of 3-hourly observed and modeled 2-m temperature during the $40 \mathrm{yr}$ (see Fig. 5) shows a very strong linear correlation with only a handful of modeled temperatures that depart significantly from those observed. Table 2 presents the statistics that quantify model performance for daily maximum $T_{\mathrm{MAX}}$, minimum $T_{\mathrm{MIN}}$, and mean $T_{\mathrm{MEAN}}=$ $\left(T_{\mathrm{MIN}}+T_{\mathrm{MAX}}\right) / 2$ temperature using statistical measures based on formulas by Willmott (1982). The observed 2-m ambient temperature values were compared with prognostically computed temperature at the 2-m level, since with the SBL scheme there is no need for analytical extrapolation such as in Paulson (1970) or Geleyn (1988). The 2-m temperatures predicted by the urban run are consistent with meteorological observations, with a correlation coefficient of 0.96 and an index of agreement of 0.97 for $T_{\mathrm{MAX}}$ and $T_{\mathrm{MIN}}$, respectively. The daily mean temperature $\left(T_{\text {MEAN }}\right)$ is better simulated by the model with a correlation coefficient and an index of agreement of 0.98 and the lowest bias value $\left(0.34^{\circ} \mathrm{C}\right)$. 
TABLE 2. Performance statistics for daily maximum $T_{\mathrm{MAX}}$, minimum $T_{\mathrm{MIN}}$, and mean $T_{\mathrm{MEAN}}=\left(T_{\mathrm{MIN}}+T_{\mathrm{MAX}}\right) / 2$ temperature based on formulas by Willmott (1982). RMSE $E_{S Y}$ and RMSE ${ }_{U N S Y S}$ are the systematic and unsystematic root-mean-square error, respectively.

\begin{tabular}{lccrcc}
\hline \hline & Correlation & $\begin{array}{c}\text { Index of } \\
\text { agreement }\end{array}$ & $\begin{array}{c}\text { Bias } \\
\left({ }^{\circ} \mathrm{C}\right)\end{array}$ & $\begin{array}{c}\mathrm{RMSE}_{\mathrm{SYS}} \\
\left({ }^{\circ} \mathrm{C}\right)\end{array}$ & $\begin{array}{c}\mathrm{RMSE}_{\mathrm{UNSY}} \\
\left({ }^{\circ} \mathrm{C}\right)\end{array}$ \\
\hline$T_{\mathrm{MAX}}$ & 0.96 & 0.97 & 1.12 & 1.38 & 2.33 \\
$T_{\text {MIN }}$ & 0.96 & 0.97 & -0.43 & 0.66 & 1.89 \\
$T_{\text {MEAN }}$ & 0.98 & 0.98 & 0.34 & 0.81 & 1.69 \\
\hline
\end{tabular}

The systematic root-mean-square error (RMSE $\left.E_{S Y S}\right)$, which should account for physical processes that the model does not routinely simulate well, is small compared to the unsystematic root-mean-square error (RMSE $\mathrm{UNSYS}_{\mathrm{S}}$. The proportions of systematic errors in the model are $26 \%, 11 \%$, and $18 \%$ for $T_{\mathrm{MAX}}, T_{\mathrm{MIN}}$, and $T_{\text {MEAN }}$, respectively. The minimum temperature is better simulated by the model with a minor negative bias of $0.43^{\circ} \mathrm{C}$ and $\mathrm{RMSE}_{\mathrm{SYS}}$ of $0.66^{\circ} \mathrm{C}$ against $1.12^{\circ}$ and $1.38^{\circ} \mathrm{C}$ for maximum temperature.
Figure 6 shows time series of monthly average daily mean temperature $\left(T_{\text {MEAN }}\right)$ observed and simulated by the urban run; the term "monthly" refers to the average of mean daily data in that month. It can be seen that the model captures quite well the intraseasonal, interannual, and interdecadal variability. This figure demonstrates also that the model is able to produce a consistent climatology for the BCR area.

\section{b. Estimation of mean urban bias on the temperature record of Uccle}

It is expected that a change in the land use forcing should have an imprint on long-term near-surface temperature records. This effect was first detected via a significance test of the differences in 2-m temperatures between the urban and rural scenarios. The statistical filter Mann-Whitney $U$ test was applied to the time series of the monthly means maximum and minimum temperature and to the diurnal temperature range (DTR = maximum - minimum temperature). Both $T_{\mathrm{MIN}}$ and DTR have high Mann-Whitney $z$ values (4.00 and 7.30, respectively), which indicates that the difference between
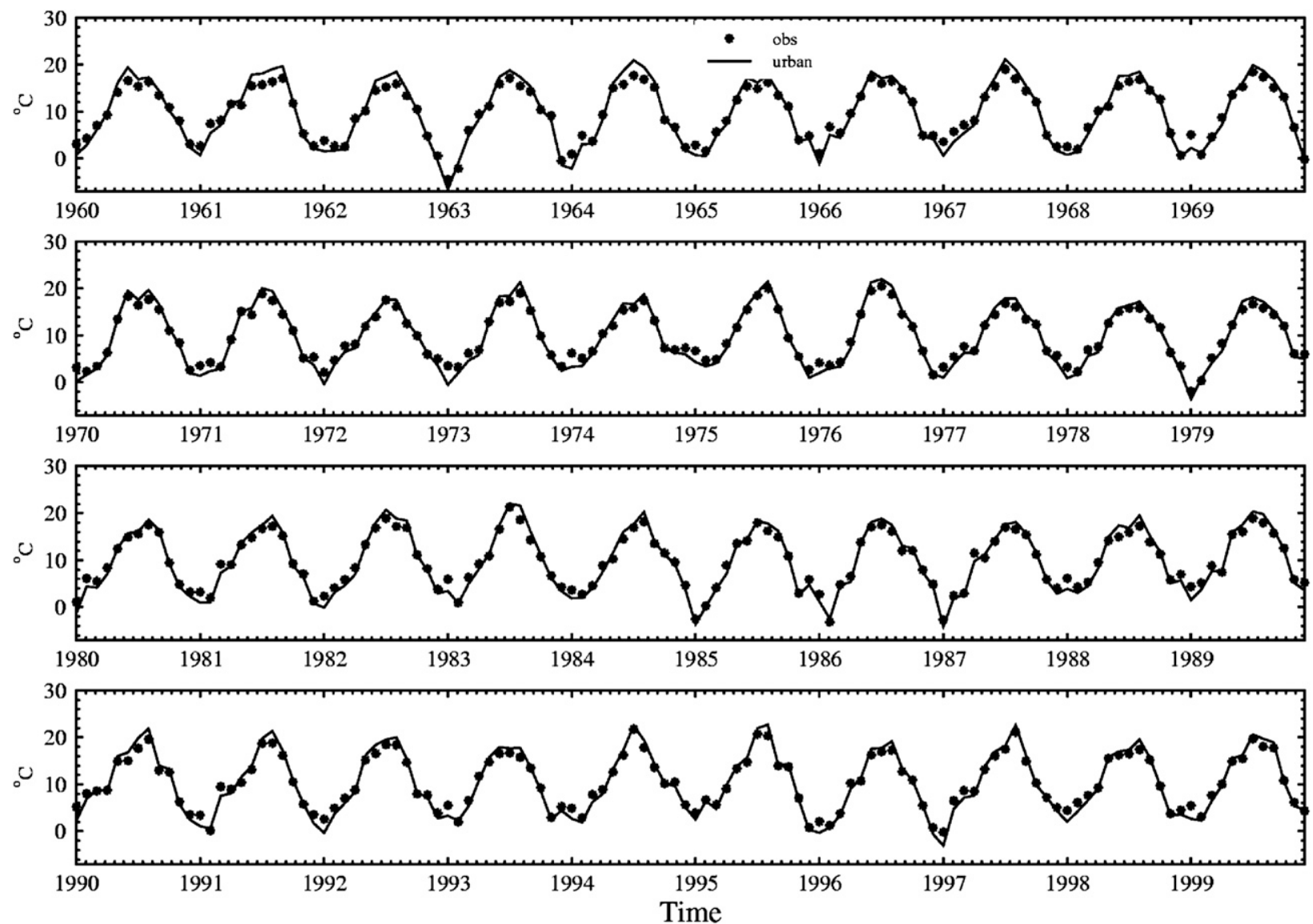

FIG. 6. The monthly mean daily average temperature $\left(T_{\text {MEAN }}\right)$ observed and simulated by the urban run (the term "monthly" refers to the mean of average daily data in that month). 


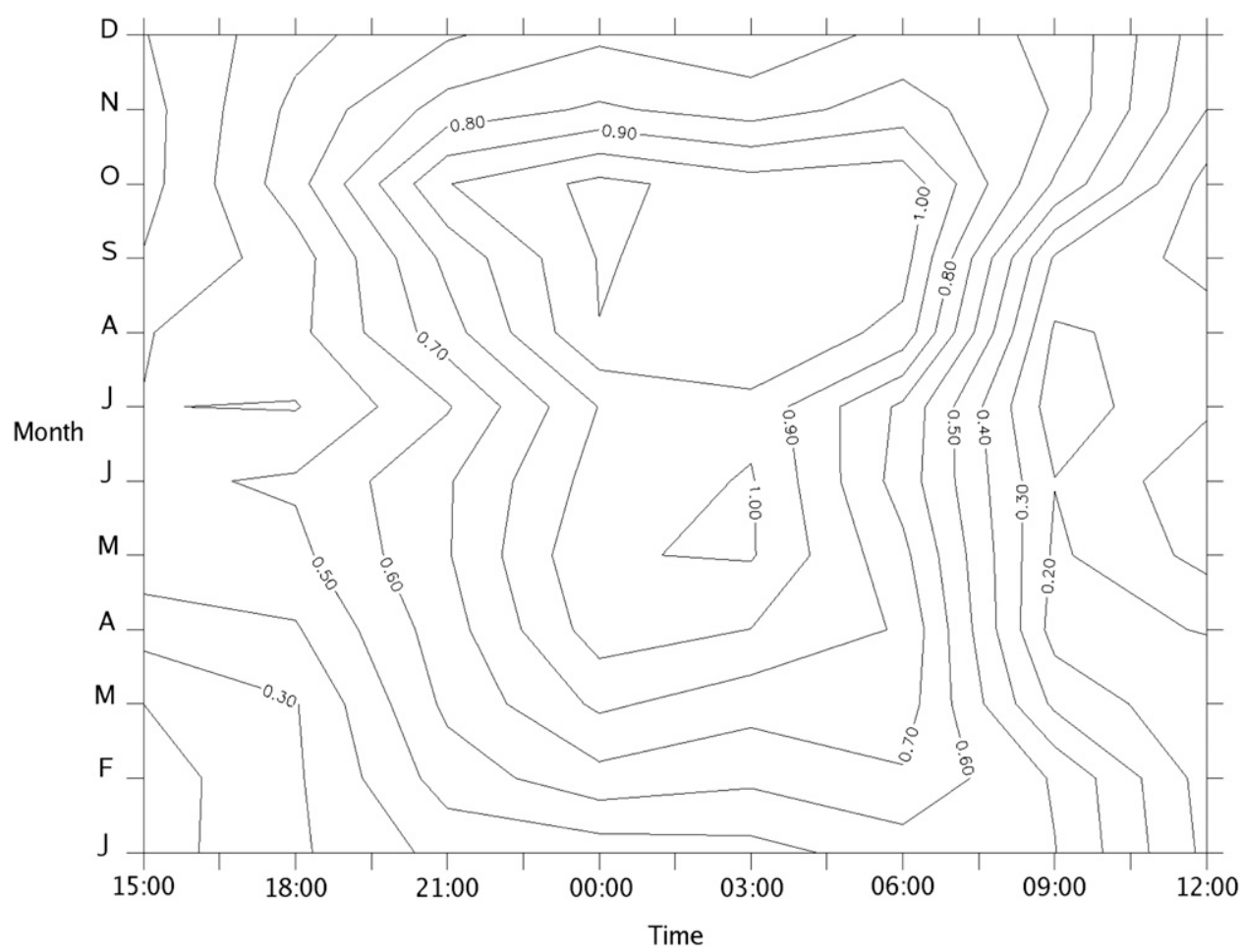

FIG. 7. Isodiagram of daily ( $x$ axis; LT) and monthly ( $y$ axis) variation of the 40-yr average urban bias.

the urban and rural scenarios is highly significant at the $95 \%$ (1.96) confidence level; $T_{\text {MAX }}$ has a positive value (0.68) but it is not significant at the $95 \%$ confidence level. The effect on minimum temperature seems to be more important than on maximum temperature, which is in agreement with the finding of Van Weverberg et al. (2008). This is to be expected, since the UHI is best observed at night when radiative cooling differences are maximized between urban and surrounding rural areas (Hamdi and Schayes 2008).

The urban bias on the temperature record of Uccle is estimated as the difference between the 2-m ambient temperature of the urban and the rural simulations $\left(\Delta T_{U-R}\right)$. It can further be noticed that even if the forcing level using by the SBL scheme is relatively high $(50 \mathrm{~m})$, we may miss the vertical structure of the UHI that would be present at $50 \mathrm{~m}$ of height. However, at this level the UHI intensity is less than at the surface because of the rapid increase of temperature in the rural area during nighttime stable conditions where the UHI is best observed.

Figure 7 presents an isodiagram of daily and monthly variation of the mean urban bias during the $40 \mathrm{yr}$ of the simulated period. A positive urban bias on the temperature record was found during the day and the night and for all seasons. During the day, temperature was hardly modified by the urban conditions with a maximum urban bias of about $0.3^{\circ} \mathrm{C}$ during summer [June-August (JJA)].
Not surprisingly, the most important influence of the urban effect on the temperature record at the Uccle site was found at nighttime (between 2100 and 0600 LT) with an urban bias of about $1^{\circ} \mathrm{C}$ during the warm season [May-September (MJJAS)]. It should be noted also that the strongest gradients are found during the warm season at sunset/sunrise with a rapid increase/decrease of the urban bias.

The 40-yr annual mean urban bias (AMUB) on mean temperature $\left(T_{\text {MEAN }}\right)$ at Uccle is $0.62^{\circ} \mathrm{C}$. Based on the classification and the relative frequencies of weather events, Van Weverberg et al. (2008) found a somewhat higher value. They estimated the weighted average UHI at the Uccle recording station to be $0.8^{\circ} \mathrm{C}$. However, the authors used a very simple parameterization for representing urban land and the selected weather events in their study presented a too small sample to make a reliable weighted average for the annual urban effect. Furthermore, the relocation of the meteorological station from the Gate of Schaerbeek in the city center of Brussels to the Plateau of Uccle in 1890 was not taken into account in their study. This aspect is not relevant for the part of the time series studied in this paper but it is important when studying the long-term urban effect since the nineteenth century. Vandiepenbeeck (1998) applied an observational approach to assess the average UHI contribution between 1966 and 1995. He studied 


\section{Annual trend}

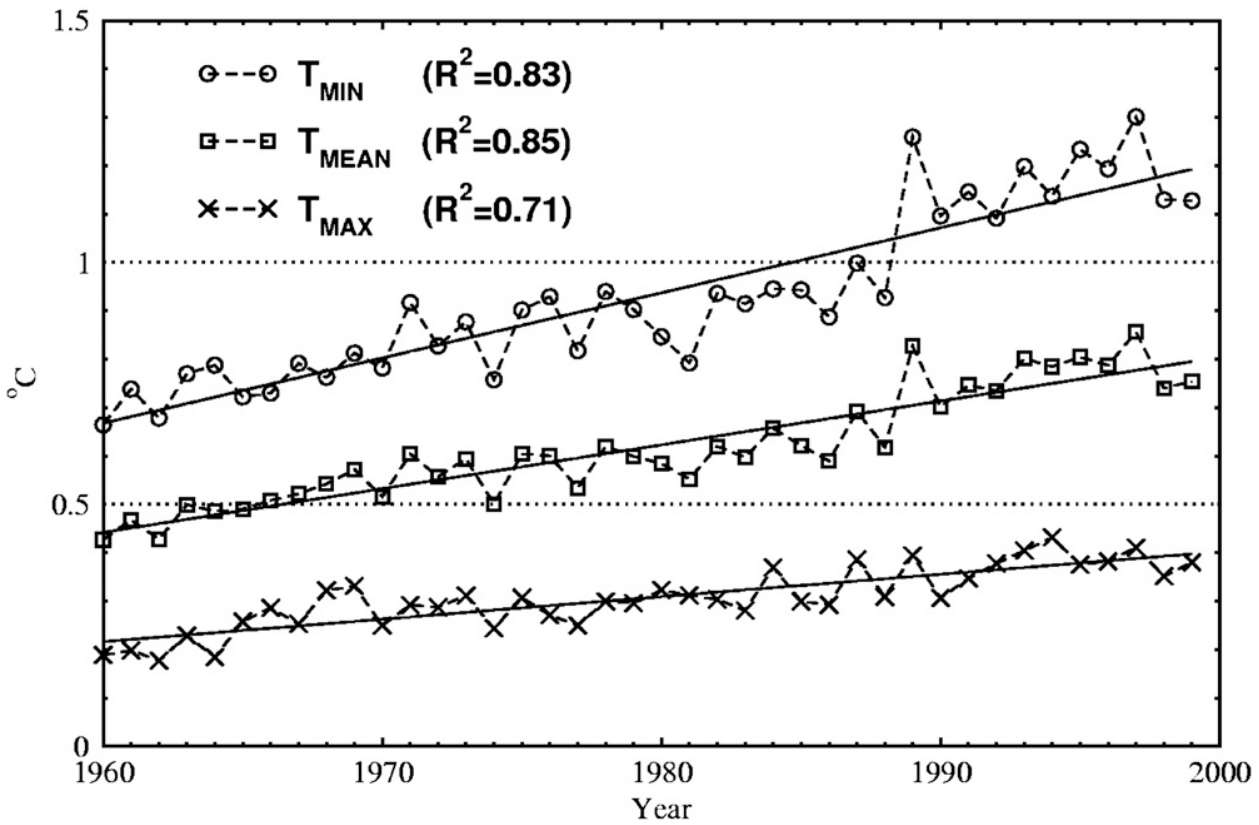

FIG. 8. AMUB in minimum ( $\left.T_{\text {MIN }}\right)$, mean $\left(T_{\text {MEAN }}\right)$, and maximum ( $\left.T_{\text {MAX }}\right)$ temperature with the linear trends, 1960-99. Here $R^{2}$ is the coefficient of determination. The annual mean is the average of the 12 months of data for the year.

the influence of urban heat advection on the temperature time series of Uccle empirically by comparing the meteorological observation with those of the rural station Saint-Hubert far away from Brussels (more than $100 \mathrm{~km}$ ). He examined the dependence of the temperature differences on wind direction. He found the annual mean urban heat contamination to be $0.55^{\circ} \mathrm{C}$, which is close to the value found in this study. However, when using an observational approach one should choose a rural station having the same climate as Uccle and located outside of the city's influence but not so far.

\section{c. Estimation of urban bias on the annual trend}

Estimates of urban bias at the Uccle recording station on maximum, minimum, and mean temperature calculated for each year, 1960-99, are plotted with the linear trends as annual time series in Fig. 8 (the annual mean is the average of the 12 months of the year). In our model for evaluating urban bias, the time series acts as a surrogate for the increase in impermeable surfaces. It can further be noticed that urban bias is not equal to zero at the beginning of the simulations because the urbanization occurred during the year 1960 .

As indicated by the spacing between the curves in Fig. 8, annual mean urban bias on minimum temperature is shown to be rising at a higher rate (almost 3 times more) than on maximum temperature, with a linear trend of $0.14^{\circ}$ and $0.05^{\circ} \mathrm{C}(10 \mathrm{yr})^{-1}$, respectively. This result is consistent with previous work suggesting that the maximum temperature is substantially less affected by urbanization than the minimum temperature (Landsberg 1981). The increase of AMUB on minimum temperature may be attributed to (i) the higher thermal inertia, which, in combination with lower albedo of urban surfaces (0.08-0.25), delays the cooling of the cities at night compared to rural areas; (ii) the limited evapotranspiration that prevents evaporative cooling of urban areas; or (iii) during night hours, the contribution of anthropogenic heat can also influence the long-term trend of temperature.

Using daily maximum and minimum temperature records (1941-2000) from stations located in the region extending from the border areas of New Mexico and Texas, southward into the Altiplano of north central Mexico, Englehart and Douglas (2003) demonstrate that a significant part of the variability in minimum temperatures for stations located in large urban areas is captured by positive linear trend, and thus is likely associated with rapid urbanization within the region. They also found that a similar but comparatively minor urban effect is apparent in the maximum temperature records for the warm season (June-September). Ezber et al. (2007) applied the Mann-Kendall trend test to minimum temperature data from stations located in urban, suburban, and rural areas in Istanbul (Turkey) to determine the 
(a) Fall

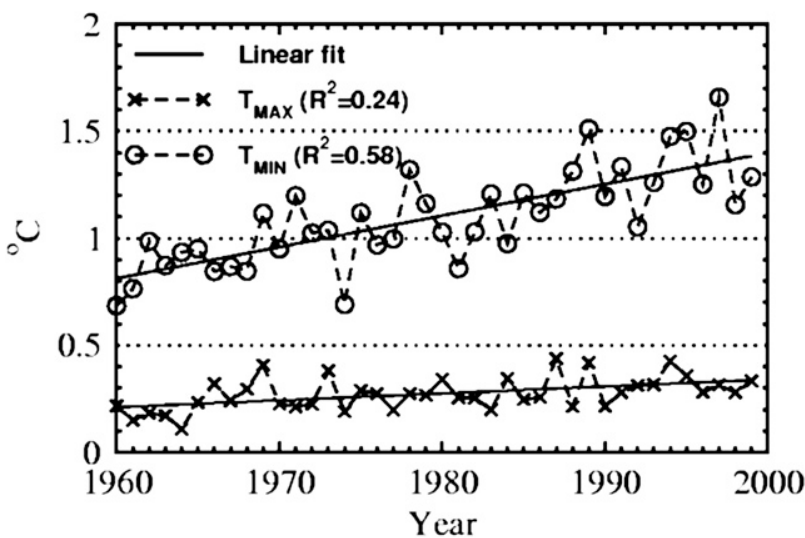

(c) Summer

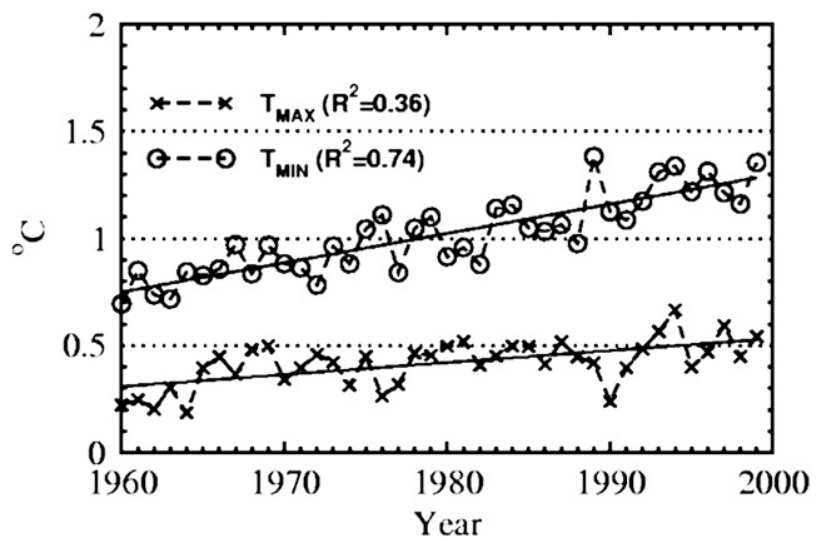

(b) Spring

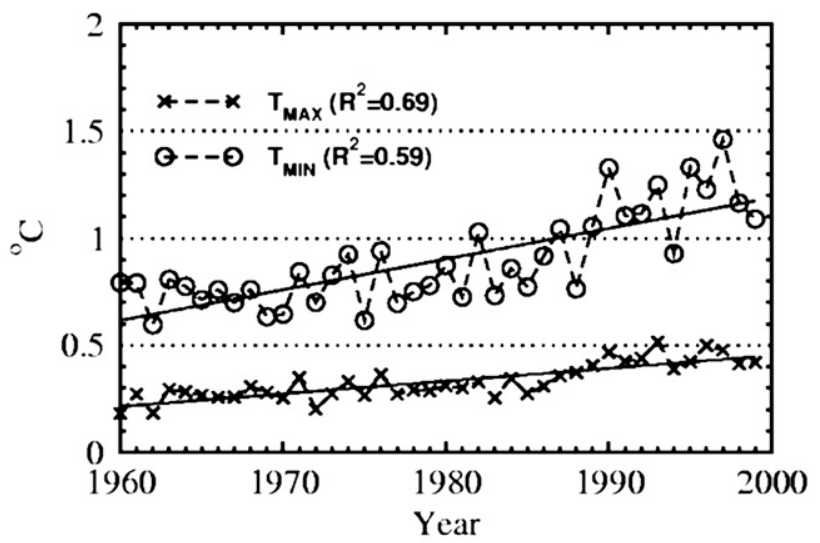

(d) Winter

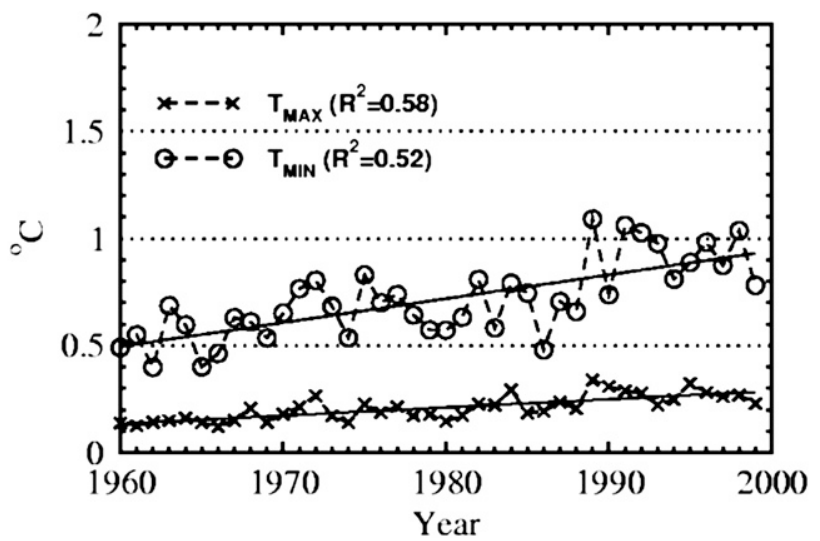

FIG. 9. SMUB on maximum $\left(T_{\mathrm{MAX}}\right)$ and minimum $\left(T_{\mathrm{MIN}}\right)$ temperature with the linear trends, 1960-99. Here $R^{2}$ is the coefficient of determination. The four seasonal means are the average of each 3-month season: winter (DJF), spring (MAM), summer (JJA), and fall (SON).

existence and significance of trends. Mann-Kendall tests indicated statistically significant positive trends in the time series of the differences in minimum temperatures between urban and rural stations, and they concluded that urbanization was the reason behind the increase in the minimum temperature in Istanbul. Ren et al. (2007) studied urbanization-induced change in annual mean maximum and minimum temperature at Wuhan station (China) for 1961-2000. They estimated trends of minimum and maximum temperature to be $0.37^{\circ}$ and $0^{\circ} \mathrm{C}$ $(10 \mathrm{yr})^{-1}$, respectively, indicating a much more evident warming at night. Recently, Shouraseni and Yuan (2009) examined the long-term trends in extreme summer season temperatures across the Twin Cities metropolitan area (Minnesota) associated with urbanization. They assembled maximum and minimum temperatures from 1975 to 2002 for seven stations located in both rural and urban areas. Their results indicated a greater rate of increase in overall minimum temperature, resulting in a slightly declining trend in diurnal temperature range.
Using the AMUB on mean temperatures, we now estimate that $45 \%{ }^{1}$ (ratio between the linear trend of the AMUB and the urban scenario) of the overall warming trend is attributed to intensifying urban heat island effects rather than to changes in local-regional climate. This should correspond to $\sim 0.63^{\circ} \mathrm{C}$ of the twentiethcentury warming trend of $1.4^{\circ} \mathrm{C}$ in the Uccle series (Yan et al. 2002).

\section{d. Seasonal trend}

Estimates of seasonal mean urban bias (SMUB) on maximum and minimum temperature calculated for each year, 1960-99, are plotted with the linear trends in Fig. 9. In Fig. 10, we present an isodiagram of daily and annual variation of the seasonal mean urban bias. The four seasonal means are the averages of each three-month season:

\footnotetext{
${ }^{1}$ The linear trends of the urban and rural scenarios were found to be $0.20^{\circ}$ and $0.11^{\circ} \mathrm{C}(10 \mathrm{yr})^{-1}$, respectively.
} 
(a) Fall

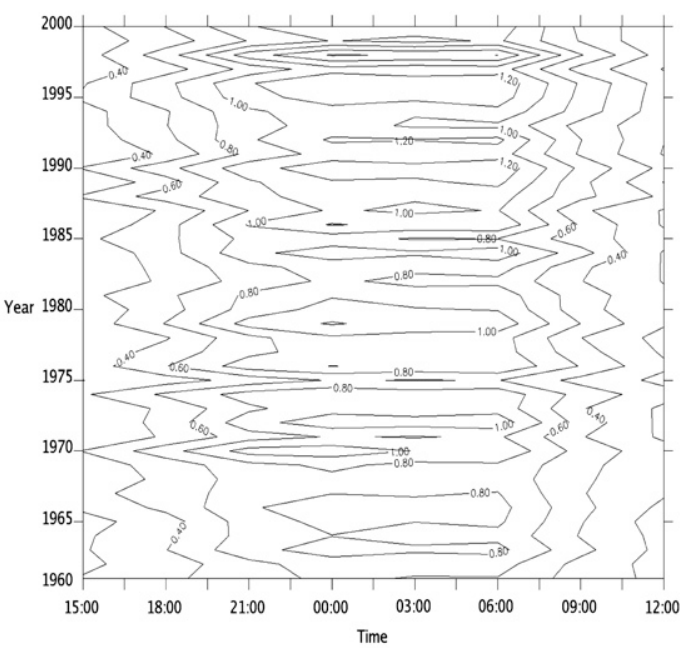

(c) Summer

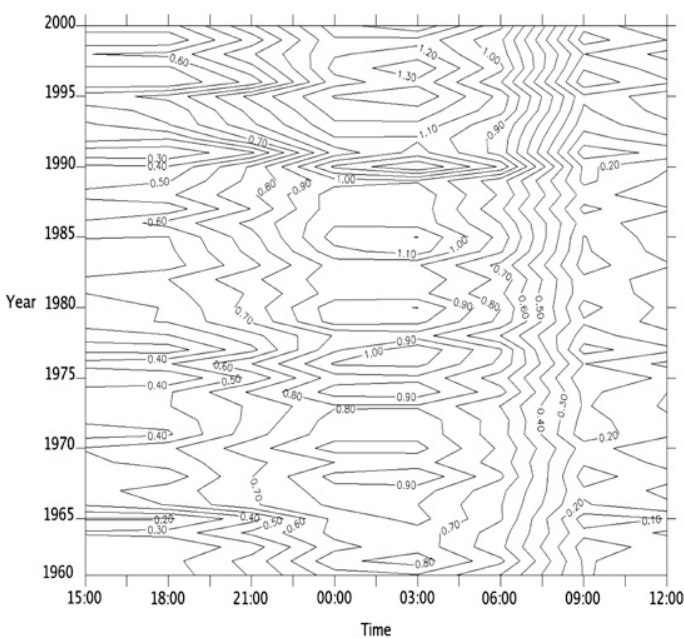

(b) Spring

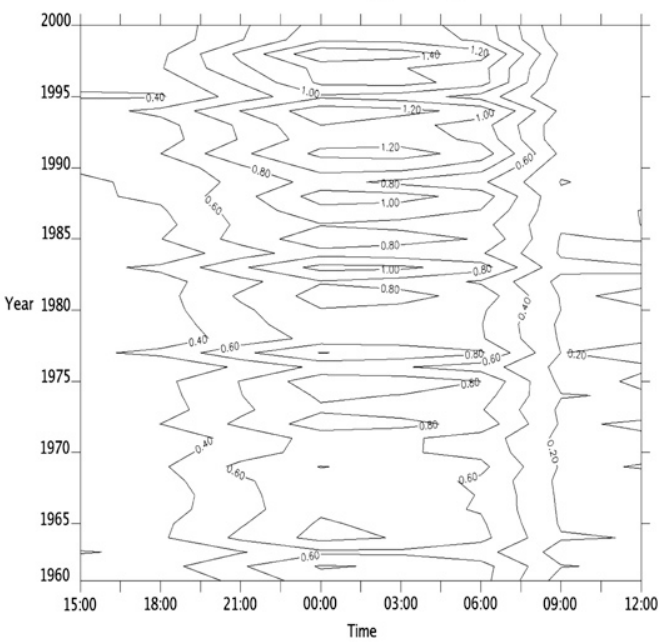

(d) Winter

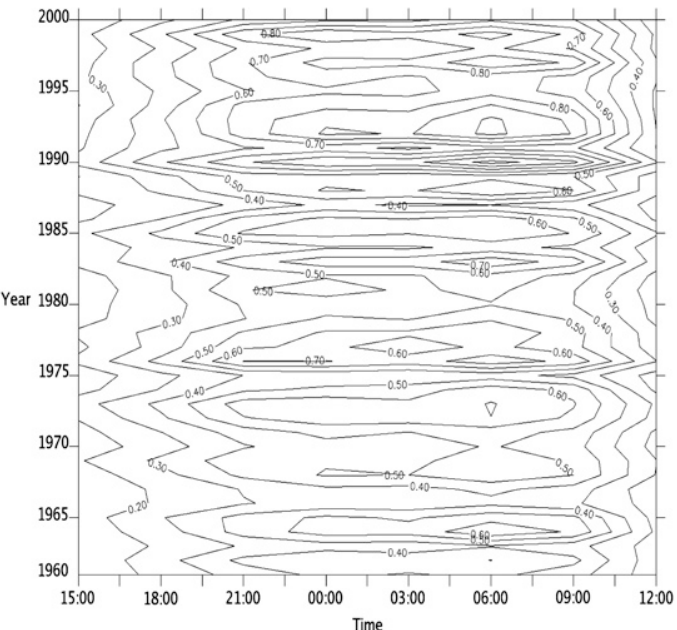

FIG. 10. Isodiagram of daily ( $x$ axis; LT) and annual ( $y$ axis) variation of the seasonal mean urban bias.

winter [December-February (DJF)], spring [March-May (MAM)], summer (JJA), and fall [September-November (SON)]. Table 3 lists estimates of the 40-yr mean magnitude and linear trend of urban bias in annual and seasonal temperatures.

\section{1) Minimum temperature}

The SMUB on minimum temperature shows increasing trends throughout the four seasons (Fig. 9). Fitting coefficients of the linear trend are $0.15^{\circ}, 0.14^{\circ}$, $0.14^{\circ}$, and $0.11^{\circ} \mathrm{C}(10 \mathrm{yr})^{-1}$ for fall, spring, summer, and winter, respectively. During summertime, the coefficient of determination is maximum $\left(R^{2}=0.74\right)$, which indicates a stronger dependence between the increase of SMUB on $T_{\mathrm{MIN}}$ and the changes in the percentage of impervious surfaces. This result agrees well with the observational study of Shouraseni and Fei (2008), who found a greater rate of increase in summertime minimum temperature accompanied with the simultaneous increase in the percentage of impervious surfaces. In fact, during summer the surface energy balance is governed by the higher shortwave radiation. Since the impermeable materials have greater specific

TABLE 3. Estimates of 40-yr mean magnitude and linear trend of urban bias in annual and seasonal temperatures.

\begin{tabular}{llccccc}
\hline \hline & & Fall & Spring & Summer & Winter & Annual \\
\hline$T_{\text {MAX }}$ & Mean & 0.27 & 0.33 & 0.42 & 0.21 & 0.31 \\
& Trend & 0.13 & 0.24 & 0.22 & 0.15 & 0.18 \\
$T_{\text {MIN }}$ & Mean & 1.10 & 0.89 & 1.02 & 0.71 & 0.93 \\
& Trend & 0.59 & 0.57 & 0.55 & 0.45 & 0.54
\end{tabular}


heat capacity, the loss of energy absorbed by the surface will be delayed late in the afternoon and will contribute to the higher night sensible heat release (see Fig. 10c). Runnalls and Oke (2000) found, however, that this property is not observed for all impermeable materials and soils.

Another notable feature in Fig. 10c is that the strongest gradients are found after sunrise (between 0600 and 0900 LT) with a rapid decrease of the urban bias, which confirms the result presented in Fig. 7. Interestingly, during this period the urban bias is kept constant during the $40 \mathrm{yr}$ independently of the increase in the percentage of impervious surfaces. In fact, the incident energy is used by the surfaces to heat the atmosphere, for heat storage, and as an evaporation flux. Since the heat storage in artificial materials is dominant in the morning in urban areas (Lemonsu et al. 2004; Hamdi and Schayes 2008), the atmospheric warming is delayed and limited.

The minimum coefficient of determination $\left(R^{2}=0.52\right)$ with the lowest fitting coefficients $\left[0.11^{\circ} \mathrm{C}(10 \mathrm{yr})^{-1}\right]$ occurs during winter with considerable year-to-year variation (Figs. 9d, 10d), which is related to more varying meteorological conditions during winter. It seems that for the Brussels capital region the synoptic conditions are much more favorable for the development of UHI in the summer season (with more anticyclonic days) than in winter (windy conditions) even if the contribution of anthropogenic heat can be greater during winter and strongly influence $T_{\mathrm{MIN}}$. During the transition seasons (fall and spring) there are considerable year-to-year variations.

\section{2) MAXimum temperature}

There is less evidence for urban bias in the maximum temperature series (see Fig. 9). Moreover, Fig. 10 shows that during daytime (note that the night is longer during winter) the urban bias is very weak and is hardly modified with the increase in the percentage of impervious surfaces during the $40 \mathrm{yr}$. Fitting coefficients of the linear trend are $0.03^{\circ}, 0.06^{\circ}, 0.06^{\circ}$, and $0.04^{\circ} \mathrm{C}(10 \mathrm{yr})^{-1}$ for fall, spring, summer, and winter, respectively. The maximum coefficient of determination $\left(R^{2}=0.69\right)$ occurs at spring and the minimum coefficient of determination $\left(R^{2}=0.24\right)$ occurs at fall. The SMUB on maximum temperature has its larger variation during summer.

The increase in SMUB on maximum temperature was also found in the study of Trusilova et al. (2008). The objective of this study was to investigate the effects of urban land cover on the climate in Europe on local and regional scales. The authors found that an increase of $T_{\mathrm{MAX}}$, induced by urban land cover, occurs during summer and winter in regions with lower mean temperatures and higher monthly precipitation, most likely in cool, temperate climate, which is the case for the city of Brussels treated in our study.

\section{Conclusions}

This study focused on trends in maximum, minimum, and mean temperatures in response to urbanization in the Brussels capital region between 1960 and 1999. During this period the increase in impervious surfaces in BCR was very important: from $26 \%$ in 1955 to $47 \%$ in 2006, which is slightly less than double. The study was based on data from remote sensing imagery combined with a land surface model including the urban parameterization of Masson (2000), the Town Energy Balance scheme. In this study, (i) we use the land surface model in a stand-alone mode, coupled to downscaled ERA-40 data, to isolate the local effects of urban growth on near-surface temperature independent of atmospheric circulations, and (ii) we consider the BCR as a lumped urban volume and the rate of urbanization was assessed by measured changes of the percentage of impervious surfaces. This study was based on calculating the temperature difference between two model integrations corresponding to two different states of urbanization: (i) "the rural" scenario representing a hypothetical situation with no urban areas inside the BCR domain during the 40 yr (1960-99), and (ii) the "urban" scenario, which represented the climate in the presence of urban areas using the measured changes of surface cover fractions. Results from our simulations indicate the following:

1) A positive temperature contamination of the temperature record of the Uccle station (situated some $6 \mathrm{~km}$ south of the center of Brussels) is found during the day and the night and for all seasons. During the day, temperature is hardly modified by the urban conditions with a maximum urban bias of about $0.3^{\circ} \mathrm{C}$ during summer (JJA). However, the most important influence of the urban effect on the temperature record is found at nighttime (between 2100 and $0600 \mathrm{LT}$ ) with an urban bias of about $1^{\circ} \mathrm{C}$ during the warm season (MJJAS).

2) The 40-yr annual mean urban bias (AMUB) on mean temperature is estimated to be $0.62^{\circ} \mathrm{C}$ and we estimate that $45 \%$ of the overall warming trend is attributed to intensifying urban heat island effects rather than to changes in local-regional climate. This should correspond to $\sim 0.63^{\circ} \mathrm{C}$ of the twentieth-century warming trend of $1.4^{\circ} \mathrm{C}$ in the Uccle series (Yan et al. 2002).

3) AMUB on minimum temperature is shown to be rising at a higher rate (almost 3 times more) than on maximum temperature, with a linear trend estimated as $0.14^{\circ}$ and $0.05^{\circ} \mathrm{C}(10 \mathrm{yr})^{-1}$, respectively. 
4) The seasonal mean urban bias (SMUB) on minimum temperature shows increasing trends throughout the four seasons. During summertime, a stronger dependence between the increase of SMUB on $T_{\text {MIN }}$ and the changes in the percentage of impervious surfaces is found.

5) The SMUB on maximum temperature is very weak and is hardly modified with the increase in the percentage of impervious surfaces during the $40 \mathrm{yr}$.

The method presented in this study is a useful tool in estimating the urban heat island contamination in time series, countering the drawbacks of an observational approach. It would be very useful to apply this research method to other cities. Furthermore, because of its local character, the results of this study will be particularly helpful for planners in developing scenarios for future land cover changes across the Brussels capital region.

Acknowledgments. The authors are very grateful to the three anonymous reviewers. Their numerous comments were invaluable in substantially improving the presentation of this work. This work is financed by the Belgian Science Policy unit, research project 2SPP/MINMETEO.

\section{REFERENCES}

Aguilar, E., I. Auer, M. Brunet, T. C. Peterson, and J. Wieringa, 2003: Guidelines on climate metadata and homogenization. World Meteorological Organization WMO/TD 1186, 50 pp.

ALADIN International Team, 1997: The ALADIN project: Mesoscale modelling seen as a basic tool for weather forecasting and atmospheric research. WMO Bull., 46, 317-324.

Best, M. J., A. Beljaars, J. Polcher, and P. Viterbo, 2004: A proposed structure for coupling tiled surfaces with the planetary boundary layer. J. Hydrometeor., 5, 1271-1278.

Bounoua, L., A. Safia, J. Masek, C. Peters-Lidars, and M. L. Imhoff, 2009: Impact of urban growth on surface climate: A case study in Oran, Algeria. J. Appl. Meteor. Climatol., 48, 217-231.

Camuffo, D., and P. Jones, Eds., 2002: Improved Understanding of Past Climatic Variability from Early Daily European Instrumental Sources. Kluwer Academic Publishers, 392 pp.

Demarée, G. R., P. J. Lachaert, T. Verhoeve, and E. Thoen, 2002 The long-term daily central Belgium temperature (CBT) series (1767-1998) and early instrumental meteorological observations in Belgium. Climatic Change, 53, 269-293.

Englehart, P. J., and A. V. Douglas, 2003: Urbanization and seasonal temperature trends: Observational evidence from a data-sparse part of north America. Int. J. Climatol., 23, 1253-1263.

Ezber, Y., O. L. Sen, T. Kindap, and M. Karaca, 2007: Climatic effects of urbanization in Istanbul: A statistical and modeling analysis. Int. J. Climatol., 27, 667-679.

Fricke, R., and E. Wolff, 2002: The MURBANDY project: Development of land use and network databases for the Brussels area (Belgium) using remote sensing and aerial photography. Int. J. Appl. Earth Obs. Geoinform., 4, 33-50.

Geleyn, J.-F., 1988: Interpolation of wind, temperature and humidity values from the model levels to the height of measurement. Tellus, 40, 347-351.
Hamdi, R., and G. Schayes, 2007: Validation of the Martilli's urban boundary layer scheme with measurements from two midlatitude European cities. Atmos. Chem. Phys., 7, 4513-4526. , and V. Masson, 2008: Inclusion of a drag approach in the Town Energy Balance (TEB) scheme: Offline 1D evaluation in a street canyon. J. Appl. Meteor. Climatol., 47, 2627-2644.

— , and G. Schayes, 2008: Sensitivity study of the urban heat island intensity to urban characteristics. Int. J. Climatol., 28, 973-982.

Huang, L., J. Lia, D. Zhaoa, and J. Zhub, 2008: A fieldwork study on the diurnal changes of urban microclimate in four types of ground cover and urban heat island of Nanjing, China. Build. Environ., 43, 7-17.

Landsberg, H. E., 1981: The Urban Climate. International Geophysics Series, Vol. 28, Academic Press, 275 pp.

Le Moigne, P., 2009: SURFEX scientific documentation. Note de centre (CNRM/GMME) 87, Météo-France, Toulouse, France, $211 \mathrm{pp}$.

Lemonsu, A., C. S. B. Grimmond, and V. Masson, 2004: Modeling the surface energy balance of an old Mediterranean city core. J. Appl. Meteor., 43, 312-327.

Masson, V., 2000: A physically-based scheme for the urban energy budget in atmospheric models. Bound.-Layer Meteor., 94, 357-397.

, and Y. Seity, 2009: Including atmospheric layers in vegetation and urban offline surface schemes. J. Appl. Meteor. Climatol., 48, 1377-1397.

, C. S. B. Grimmond, and T. R. Oke, 2002: Evaluation of the Town Energy Balance (TEB) scheme with direct measurements from dry districts in two cities. J. Appl. Meteor., 41, 1011-1026.

- J.-L. Champeaux, F. Chauvin, C. Meriguet, and R. Lacaze, 2003: A global database of land surface parameters at $1-\mathrm{km}$ resolution in meteorological and climate models. J. Climate, 16, 1261-1282.

Noilhan, J., and S. Planton, 1989: A simple parameterization of land surface processes for meteorological models. Mon. Wea. Rev., 117, 536-549.

Paulson, C. A., 1970: The mathematical representation of wind and temperature profiles in the unstable atmospheric surface layer. J. Appl. Meteor., 9, 857-861.

Peterson, T. C., H. Daan, and P. D. Jones, 1997: Initial selection of a GCOS surface network. Bull. Amer. Meteor. Soc., 78, 2145-2152.

Pigeon, G., M. A. Moscicki, J. A. Voogt, and V. Masson, 2008: Simulation of fall and winter surface energy balance over a dense urban area using the TEB scheme. Meteor. Atmos. Phys., 102, 159-171.

Qian, J.-H., A. Seth, and S. Zebiak, 2003: Reinitialized versus continuous simulations for regional climate downscaling. Mon. Wea. Rev., 131, 2857-2874.

Ren, G. Y., Z. Y. Chu, Z. H. Chen, and Y. Y. Ren, 2007: Implications of temporal change in urban heat island intensity observed at Beijing and Wuhan stations. Geophys. Res. Lett., 34, L05711, doi:10.1029/2006GL027927.

Runnalls, K. E., and T. R. Oke, 2000: Dynamics and controls of the near-surface heat island of Vancouver, British Columbia. Phys. Geogr., 21, 283-304.

Shouraseni, S. R., and F. Yuan, 2009: Trends in extreme temperatures in relation to urbanization in Twin Cities metropolitan area, Minnesota. J. Appl. Meteor. Climatol., 48, 669-679.

Silva, H. R., R. Bhardwaj, P. E. Phelan, J. S. Golden, and S. Grossman-Clarke, 2009: Development of a zero-dimensional mesoscale thermal model for urban climate. J. Appl. Meteor. Climatol., 48, 657-668. 
Sneyers, R., 1981: Les séries climatologiques de Bruxelles-Uccle, la température de l'air. Koninklijk Meteorologisch Instituut van België Publicaties Series B, Vol. 110, 39 pp.

Trusilova, K., M. Jung, G. Churkina, U. Karstens, M. Heimann, and M. Claussen, 2008: Urbanization impact on the climate in Europe: Numerical experiments by the PSU-NCAR mesoscale model (MM5). J. Appl. Meteor. Climatol., 47, 14421455.

Uppala, S. M., and Coauthors, 2005: The ERA-40 re-analysis. Quart. J. Roy. Meteor. Soc., 131, 2961-3012.

Van de Voorde, T., J. Vlaeminck, and F. Canters, 2008: Comparing different approaches for mapping urban vegetation cover from Landsat ETM+ data: A case study on Brussels. Sensors, 8, 3880-3902.

Vandiepenbeeck, M., 1998: On a recent urban effect in the time series of the temperature in different stations in Belgium. Proc. Second European Conf. on Applied Climatology, Vienna, Austria, Österreichse Beiträge zu Meteorologie und Geophysik, 19.

Vanhuysse, S., J. Depireux, and E. Wolff, 2006: Etude de l'évolution de l'imperméabilisation du sol en région de BruxellesCapitale. Université Libre de Bruxelles, IGEAT, Brussels, Belgium, $60 \mathrm{pp}$.

Van Oldenborgh, G. J., and A. Van Ulden, 2003: On the relationship between global warming, local warming in the
Netherlands and changes in circulation in the 20th century. Int. J. Climatol., 23, 1711-1724.

- S. Drijfhout, A. Van Ulden, R. Haarsma, A. Sterl, W. Hazeleger, and H. Dijkstra, 2009: Western Europe is warming much faster than expected. Climate Past, 5, 1-12.

Van Weverberg, K., K. De Ridder, and A. Van Rompaey, 2008: Modeling the contribution of the Brussels Heat Island to a long temperature time series. J. Appl. Meteor. Climatol., 47, 976-990.

Wijngaard, J. B., A. Klein Tank, and G. Können, 2003: Homogeneity of 20th century European daily temperature and precipitation series. Int. J. Climatol., 23, 679-692.

Willmott, C. T., 1982: Some comments on the evaluation of model performance. Bull. Amer. Meteor. Soc., 63, 1309-1313.

Yan, Z., and Coauthors, 2002: Trends of extreme temperatures in Europe and China based on daily observations. Climatic Change, 53, 355-392.

Yuan, F., and M. E. Bauer, 2007: Comparison of impervious surface area and normalized difference vegetation index as indicators of surface urban heat island effects in Landsat imagery. Remote Sens. Environ., 106, 375-386.

Žagar, N., M. Žagar, J. Cedilnik, G. Gregorič, and J. Rakovec, 2006: Validation of mesoscale low-level winds obtained by dynamical downscaling of ERA-40 over complex terrain. Tellus, 58A, 445-455. 